\title{
Stubborn hiccups as a sign of massive apoplexy in a naive acromegaly patient with pituitary macroadenoma
}

\author{
Gulay Simsek Bagir', Soner Civi², Ozgur Kardes², Fazilet Kayaselcuk ${ }^{3}$ and \\ Melek Eda Ertorer \\ Departments of ${ }^{1}$ Endocrinology, ${ }^{2}$ Neurosurgery, and ${ }^{3}$ Pathology, Baskent University Faculty of Medicine, \\ Adana, Turkey
}

\author{
Correspondence \\ should be addressed \\ to $\mathrm{G}$ Simsek Bagir \\ Email \\ gulaysimsekbagir@yahoo. \\ com
}

\section{Summary}

Pituitary apoplexy (PA) may very rarely present with hiccups. A 32-year-old man with classical acromegaloid features was admitted with headache, nausea, vomiting and stubborn hiccups. Pituitary magnetic resonance imaging (MRI) demonstrated apoplexy of a macroadenoma with suprasellar extension abutting the optic chiasm. Plasma growth hormone (GH) levels exhibited suppression (below $<1 \mathrm{ng} / \mathrm{mL}$ ) at all time points during $\mathrm{GH}$ suppression test with $75 \mathrm{~g}$ oral glucose. After treatment with corticosteroid agents, he underwent transsphenoidal pituitary surgery and hiccups disappeared postoperatively. The GH secretion potential of the tumor was clearly demonstrated immunohistochemically. We conclude that stubborn hiccups in a patient with a pituitary macroadenoma may be a sign of massive apoplexy that may result in hormonal remission.

\section{Learning points:}

- Patients with pituitary apoplexy may rarely present with hiccups.

- Stubborn hiccupping may be a sign of generalized infarction of a large tumor irritating the midbrain.

- Infarction can be so massive that it may cause cessation of hormonal overproduction and result in remission.

\section{Background}

Pituitary apoplexy is a term used for hemorrhage or infarction of pituitary adenomas. It is usually observed in patients with nonfunctioning adenomas; however, apoplexy of other tumor types, like prolactinomas and GH-secreting adenomas have been reported before $(1,2)$. Headache is its main symptom, and visual disturbances and/or ocular palsy can sometimes accompany (3). Apoplexy may very rarely present with hiccups, which is probably due to midbrain involvement (4).

Although PA is often followed by hypopituitarism in nonfunctioning adenomas, functioning ones occasionally demonstrate hormonal remission after an apoplectic episode. Accordingly, spontaneous remission of acromegaly due to apoplexy has been reported before $(5,6,7)$.

Herein, we report the case of an undiagnosed acromegalic man with infarctive pituitary apoplexy and stubborn hiccups who demonstrated normal GH dynamics and serum insulin-like-growth factor type 1 (IGF1) level at presentation and became growth hormone deficient following decompression surgery.

\section{Case presentation}

A thirty-two-year-old man was admitted to our out-patient clinic with the story of headache, nausea, vomiting and 
stubborn hiccups that began five days before. On physical examination, he has most of the physical features of acromegaly; thickening of facial skin and typical acromegalic face, increased hand, finger and foot size. He had dehydration and hypotension on admission.

\section{Investigation}

His hormonal profile was thyroid-stimulating hormone: $0.007 \mathrm{pmol} / \mathrm{L}$ (0.4-4.6), free thyroxine: $12.2 \mathrm{pmol} / \mathrm{L}$ (11.522.7), random cortisol: $4.71 \mu \mathrm{g} / \mathrm{dL}(4.3-22.4)$, folliclestimulating hormone: $2.52 \mathrm{IU} / \mathrm{mL}(1.42-15.4)$, luteinizing hormone: $1.14 \mathrm{IU} / \mathrm{mL}(1.24-7.8)$, total testosterone: $0.0 \mathrm{ng} / \mathrm{mL} \quad(2.41-8.27)$ and prolactin: $0.43 \mathrm{ng} / \mathrm{mL}$
(2.1-17.7). His IGF1 was normal $(229 \mathrm{ng} / \mathrm{mL} ; 119-307)$ with random GH: $2.53 \mathrm{ng} / \mathrm{mL}(0.0-3.0)$.

Pituitary MRI demonstrated an adenoma with suprasellar extension abutting the optic chiasm, showing ring enhancement with gadolinium. The images were compatible with apoplexy (Fig. 1).

Diagnostic work-up for hiccups was performed, including biochemical analyses for renal and hepatic functions, electrocardiogram for ruling out myocardial infarction, X-ray of the chest and abdominal ultrasound for eliminating diaphragm irritation, neurological and otolaryngologic examination. All were found to be negative. He denied alcohol consumption or medication use.
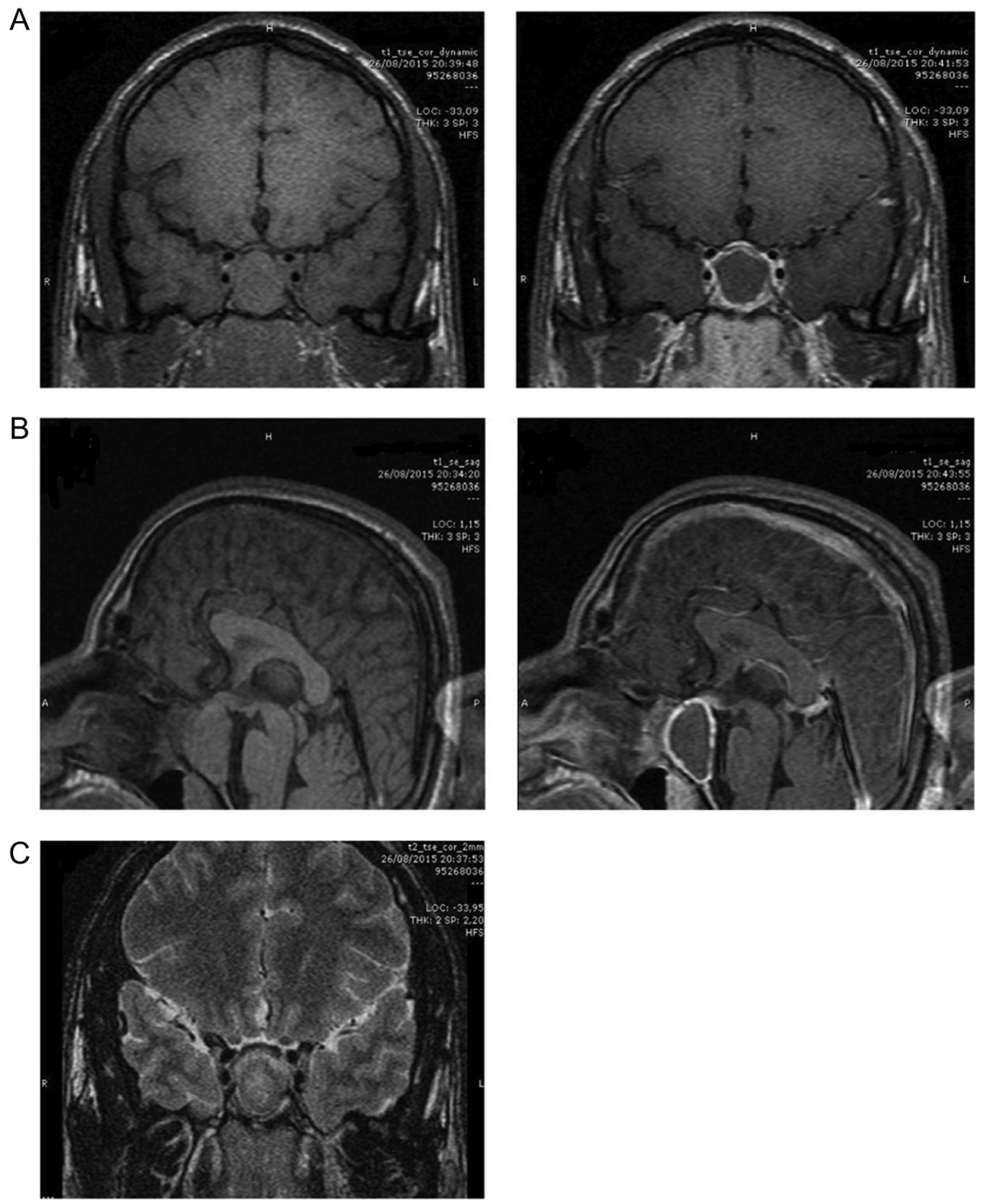

Figure 1

MRI findings of the patient on admission. (A) Pre- and post-contrast coronal T1-weighted images showing an heterogeneous pituitary mass with suprasellar extension abutting the optic chiasm and ring enhancement with gadolinium. (B) Pre and Post-contrast sagittal T1-weighted images. (C) Coronal T2 -weighted image. T1-weighted hyperintense areas and T2-weighted hypointense areas within sellar mass are consistent with pituitary apoplexy. 
On the third day of his admission, growth hormone suppression test with $75 \mathrm{~g}$ oral glucose was performed. His plasma GH levels exhibited suppression (below $<1 \mathrm{ng} / \mathrm{mL}$ ) at all time points.

\section{Treatment}

Urgent treatment with intravenous glucocorticoids and fluids were introduced and he dramatically improved within few hours of treatment and the frequency of hiccups decreased, although not completely disappeared.

On the sixth day of admission, he underwent transsphenoidal pituitary surgery. The tumor was removed with preservation of the surrounding gland.

\section{Outcome and follow-up}

The patient did well postoperatively, and the hiccups completely disappeared. The tumor was semi-rigid and was gray in color with no hemorrhage at gross examination. Histological work-up demonstrated an adenoma with ischemic necrosis and absence of hemorrhage. Immunohistochemical staining exhibited GH and prolactin positivity over $90 \%$ (Fig. 2).

At follow-up, he demonstrated central hypogonadism and hypothyroidism with intact cortisol axis. He was GH deficient both at the first and third postoperative month (GH: 0.2 and $0.16 \mathrm{ng} / \mathrm{mL}, \quad$ IGF1: 86.7 and $85.5 \mathrm{ng} / \mathrm{mL}$, respectively).

\section{Discussion}

Pituitary apoplexy is a life-threatening, clinical syndrome of pituitary infarction with hemorrhage and/or necrosis. Precipitating factors cannot be identified in all cases. The most relevant clinical situations associated with PA are angiographic procedures, surgery, closed head trauma, dynamic tests and drugs (3). Most commonly presenting symptoms are headache, ophthalmoplegia, nausea and/or vomiting. The clinical manifestations of PA are related to underlying pathological mechanism, including increased intrasellar pressure, mass effect, compression of neighboring structures and nerves within the cavernous sinus and/or subarachnoid hemorrhage. Apoplexy may
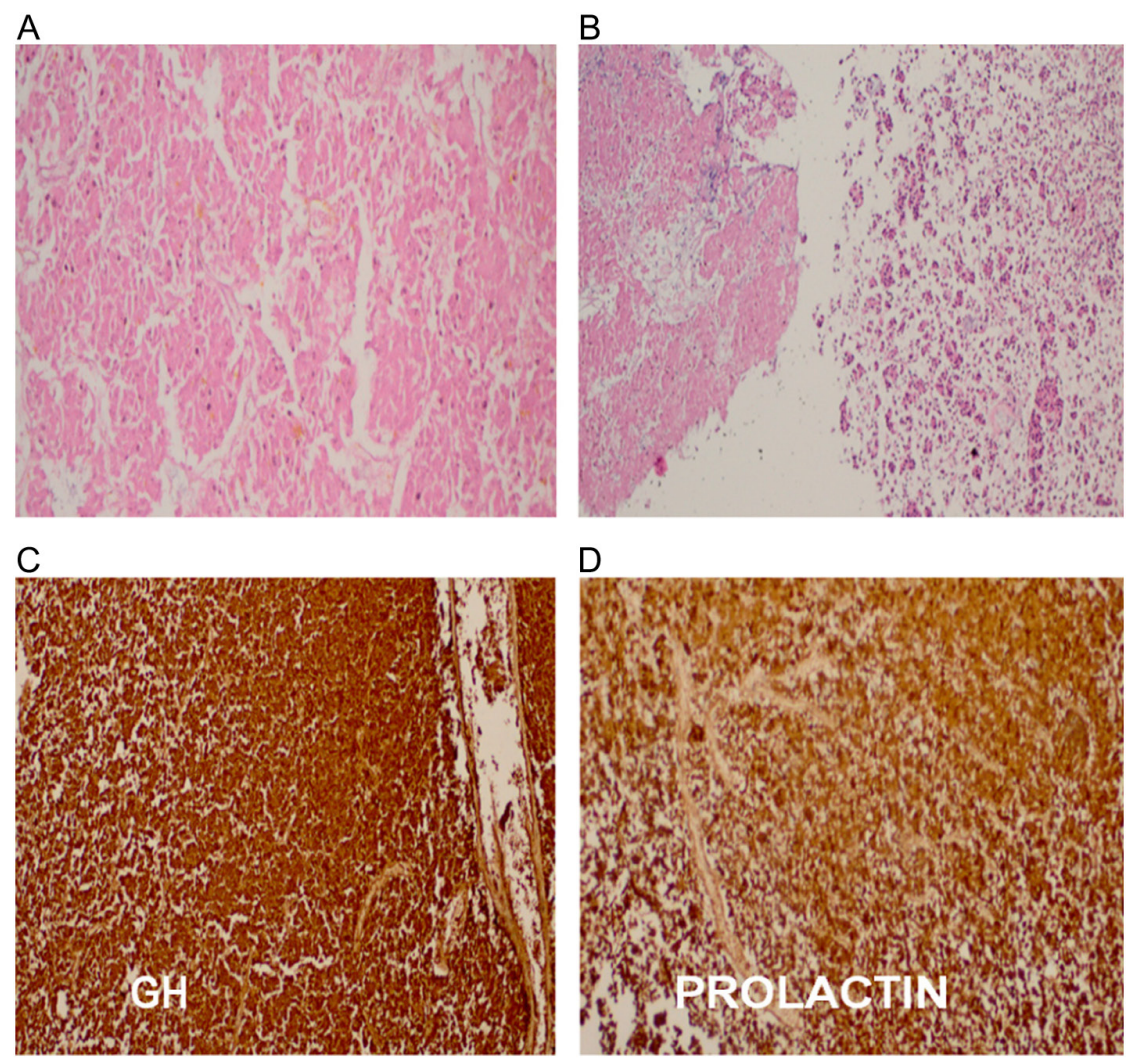

Figure 2

Pathological and immunhistochemical work-up of the operation specimen. The histology of the tumor showed a necrotic adenoma (A) with extensive areas of necrosis $(B)$ (hematoxylineosin stain $\times 100$ ). Most of the necrotic cells were immunopositive for $\mathrm{GH}$ and prolactin $(C, \mathrm{D})(\mathrm{immunohistochemistry} \times 200$ ). 
very rarely present with hiccups, which is probably due to midbrain involvement.

Pituitary apoplexy is usually observed in patients with nonfunctioning adenomas. When it arises in functional adenomas, it may result in spontaneous remission due to massive necrosis or hemorrhage (8). Accordingly, the potential functioning nature of the adenoma that undergoes apoplexy may not be assessed due to the extensive necrosis.

Partial or complete hypopituitarism is evident in most patients at presentation. Acute adrenal insufficiency is the most common deficit. It is also the most life-threatening hormonal complication, and corticosteroid supplementation should be given to all these patients immediately.

This is a very rare naive case of acromegaly with pituitary macroadenoma who presented with infarctive apoplexy and stubborn hiccups and normal GH dynamics. The GH secretion potential of the tumor was clearly demonstrated immunohistochemically.

Hiccups are involuntary contractions of the diaphragm. Brief episodes are usually benign and selflimiting but prolonged attacks are frequently associated with an underlying pathologic process. A reflex arc involving peripheral phrenic, vagal and sympathetic pathways and central midbrain modulation is responsible for hiccups (9). Accordingly, any physical and chemical factors, inflammation and neoplasia invading the arc may cause hiccups.

Hiccup is a rare symptom of acute apoplexy, which is attributed to the involvement of central processing unit in the midbrain. Although the exact pathophysiological mechanisms have not been clearly demonstrated till now, elevation in intrapituitary pressure due to apoplexy may be an explanation for the hiccups of this individual case (10). Hypothetically, it may be proposed to be a sign of generalized infarction of the large tumor irritating the midbrain. This infarction was so massive that he had normal GH dynamics even though he exhibited clear signs of acromegaly on admission. Surprisingly, his serum IGF1 level was low, and this might be explained by possible subclinical pituitary infarctions he experienced within the previous months. Stubborn hiccups in a patient with a pituitary macroadenoma may be a sign of massive apoplexy.

\section{Declaration of interest}

The authors declare that there is no conflict of interest that could be perceived as prejudicing the impartiality of the research reported.

\section{Funding}

This research did not receive any specific grant from any funding agency in the public, commercial or not-for-profit sector.

\section{Patient consent}

Written informed consent has been obtained from the patient for publication of the case report and the accompanying images.

\section{Author contribution statement}

G S Bagir was responsible for case description, literature review and writing; S Civi and Özgür K are neurosurgeons; F K Selcuk performed histological studies and provided clinical care for the patient; M E Ertorer was responsible for case description, literature review and editing.

\section{References}

1 Jiang HJ, Hung WW \& Hsiaso PJ 2013 A case of acromegaly complicated with diabetic ketoacidosis, pituitary apoplexy, and lymphoma. Kaohsiung Journal of Medical Science 29 687-690. (doi:10.1016/j.kjms.2013.08.002)

2 Nganga HK \& Lubanga RP 2013 Pituitary macroadenoma presenting with pituitary apoplexy, acromegaly and secondary diabetes mellitus - a case report. Pan African Medical Journal 15 39. (doi:10.11604/ pamj.2013.15.39.2054)

3 Briet C, Salenave S, Bonneville JF, Laws ER \& Chanson P 2015 Pituitary apoplexy. Endocrine Reviews 36 622-645. (doi:10.1210/er.2015-1042)

4 Famini P \& Melmed S 2014 Pituitary apoplexy. In Endocrine Emergencies: Recognition and Treatment, pp 175-213. Ed L Loriaux. Springer.

5 Nishioka H, Haraoka J \& Miki T 2005 Spontaneous remission of functioning pituitary adenomas without hypopituitarism following infarctive apoplexy: two case reports. Endocrine Journal 52 117-123. (doi:10.1507/endocri.52.117)

6 Roerink SH, van Lindert EJ \& van de Ven AC 2015 Spontaneous remission of acromegaly and Cushing's disease following pituitary apoplexy: two case reports. Netherlands Journal of Medicine $\mathbf{7 3}$ 242-246. (doi:10.13070/rs.en.1.769)

7 Mir SA, Masoodi SR, Bashir MI, Wani AI, Farooqui KJ, Kanth B \& Bhat AR 2013 Dissociated hypopituitarism after spontaneous pituitary apoplexy in acromegaly. Indian Journal of Endocrinology and Metabolism 17 102-104. (doi:10.4103/2230-8210.119518)

8 Villar-Taibo R, Ballesteros-Pomar MD, Vidal-Casariego A, AlvarezSan Martin RM, Kyriakos G \& Cano-Rodriguez I 2014 Spontaneous remission of acromegaly: apoplexy mimicking meningitis or meningitis as a cause of apoplexy? Arquivos Brasileiros de Endocrinologia and Metabologia 58 76-80. (doi:10.1590/00042730000002701)

9 Chang FY \& Lu CL 2012 Hiccup: mystery, nature and treatment. Journal of Neurogastroenterology and Motility 18 123-130. (doi:10.5056/ jnm.2012.18.2.123)

10 Zayour D, Selman W \& Arafah B 2004 Extreme elevation of intrasellar pressure in patients with pituitary tumor apoplexy: relation to pituitary function. Journal of Clinical Endocrinology and Metabolism 89 5649-5654. (doi:10.1210/jc.2004-0884)

Received in final form 7 April 2017

Accepted 19 April 2017 